\title{
Empirical Analysis of Resident Income and Economic Growth in Guangxi, China
}

\author{
Junjun Zhang ${ }^{1,2, *}$, Ke Gao ${ }^{3,4, *}$ \\ ${ }^{1}$ The School of Finance and Taxation, Central University of Finance and Economics, Beijing, P.R. China \\ ${ }^{2}$ Department of Finance, Institute of Fiscal Science, Guangxi Zhuang Autonomous Region, P.R. China \\ 3“The Belt and Road" Economic Development Research Center, Shandong University of Finance and Economics, Jinan, P. R. China \\ ${ }^{4}$ Development Research Center of Shandong, Jinan, P. R. China
}

Email address:

13907865848@163.com (Junjun Zhang),gkfly@126.com (Ke Gao)

${ }^{*}$ Corresponding author

\section{To cite this article:}

Junjun Zhang, Ke Gao. Empirical Analysis of Resident Income and Economic Growth in Guangxi, China. International Journal of Economics, Finance and Management Sciences. Vol. 6, No. 4, 2018, pp. 185-191. doi: 10.11648/j.ijefm.20180604.16

Received: August 14, 2018; Accepted: September 13, 2018; Published: September 18, 2018

\begin{abstract}
This paper explores the current situation and causes of rapid economic growth but slow growth of residents' income since the reform and opening up in Guangxi China, and clarifies the relationship between income distribution and economic growth. According to the basic principles of economics, through the establishment of economic models, this paper makes an empirical analysis for the interrelated relationship between economic growth, income distribution of residents, fiscal revenue and economic structure. In this paper, Johansen cointegration test is used to test the cointegration relationship between these variables, and the results reflect the cointegration relationship between variables, which shows that the original regression is not a spurious regression. It also shows that although the series of variables are non-stationary, there is a long-term stable equilibrium relationship between GDP and variables. Then the paper leads to the following conclusions and suggestions: Residents' income plays an important role in economic growth, and income distribution should be appropriately inclined to residents. We must make full use of the means of fiscal regulation of income distribution. It is necessary to increase wage income, property income, and operating income of urban and rural residents. It is necessary to promote the optimization and adjustment of the economic structure. In the end, "both the country and the people are rich" will be realized.
\end{abstract}

Keywords: Economic Growth Model, Urban and Rural Residents’ Income, Empirical Analysis

\section{Introduction}

Since the reform and opening up, China's economy has developed rapidly. But for a long time, the growth rate of per capita income of residents is lower than that of per capita GDP, and the growth rate of per capita income is higher than that of per capita GDP (except for individual years) [1]. This shows that the government has not considered the adjustment of the redistribution of national income well while increasing the fiscal income. The income growth of urban and rural residents has not kept pace with economic growth, and urban and rural residents can't fully share the fruits of economic development [2]. Taking the Guangxi Zhuang Autonomous Region data as an example, this paper makes an empirical analysis of the correlation between economic growth and the income distribution of residents, fiscal income and so on, and illustrates the importance of the income distribution to economic growth, and puts forward some suggestions to improve the income of urban and rural residents in Guangxi.

As one of the most important sub systems of the whole economic and social system, the income distribution system not only affects the efficiency of production, the vital interests of the public, but also affects the coordination and stability of the society, and affects and restricts the development of the social economy in a considerable degree. Over the past 30 years of reform and opening up, the field of income distribution in Guangxi has broken the shackles of planned economy. It has made great progress and innovation in the aspects of theoretical research, system reform and system construction. The old concept and distribution pattern of the 
equalitarianism have basically been changed. The income of urban and rural residents has increased steadily. The social wealth of the people has improved significantly, and the living standard and quality of life of the people have improved significantly [3]. However, at the same time, problems such as inadaptability between the growth rate of income and the growth rate of economic development are also increasingly prominent. The social security system is not perfect, which leads to the imbalance and dissatisfaction of people's mentality, which has become a potential unsettled factor affecting social stability and seriously affects the further transformation of economy and society to a large extent [4].

\section{Relevant Economic Theory}

From the perspective of enterprises, a reasonable economic structure can promote economic growth. Kuznets (1971) once proposed that the measurement of the national income of a country must be measured from a structural perspective. Denison (1967) studies show that $12 \%$ of economic growth is caused by structural optimization. Economic structure optimization is conducive to the rational flow and full use of resources. Economic structure adjustment and economic growth can't be separated, because they are organic unity. Economic growth promotes the optimization of industrial structure, and the optimization of industrial structure has also brought economic growth faster [5].

From the government's point of view, a reasonable level of fiscal revenue can have a positive impact on economic development. Fiscal revenue is the income obtained from the growth of the national economy. If the level of economic development is high, the gross national product (GDP) is higher and the total fiscal revenue is correspondingly higher. At the same time, the fiscal income is very important in meeting the needs of economic development, supporting the realization of the government functions and ensuring the stable and coordinated development of the economic society. Therefore, there is a relationship of mutual promotion and mutual restraint between fiscal revenue and economic growth. The supply-side economics has put forward a system of measurement. Only a reasonable level of fiscal revenue can have a positive impact on the development of the social economy.

From the perspective of residents, there is an interactive relationship between the income of urban and rural residents and economic growth. Economic theory holds that under the conditions of effective system arrangement, reasonable economic structure and perfect government redistribution policy, sustained economic growth creates more employment opportunities, expands the employment of residents, and lays the material basis for improving the distribution of residents' income, increases the total income of the residents. Income growth is one of the main contents of economic growth, and the most obvious external manifestation of economic growth and the ultimate goal of economic growth.

From the point of view of regulation, public finance has the important function of regulating income distribution. The function of income distribution is the most basic and important function of finance. In the process of social reproduction, there is a social Initial distribution process, which is formed by the input of productive factors into the distribution of social products, and the social redistribution formed by the political power to participate in the distribution of social products. The initial distribution is the distribution activity in the market economy field, and the fiscal redistribution is the distribution activity in the economic field of the government. The principles and mechanisms of income distribution in the two fields are totally different, and how to deal with the relationship between fairness and efficiency in income distribution is also different. The initial distribution is allocated according to the input of production factors (labor, capital, land, technology, etc.). For social development and fairness, the first social distribution (the income of the residents) is important. The redistribution is the increase or decrease of income caused by non-market factors. Financial expenditure is inclined to the people's livelihood, so as to benefit the people, narrow the gap between the rich and the poor and improve the social security system.

\section{Descriptive Statistical Analysis}

\subsection{Changes in the Income Level of Urban and Rural Residents in Guangxi}

Since the reform and opening up, the income of urban and rural residents in Guangxi has been significantly improved, showing an increasing trend year by year. Among them, the per capita disposable income of urban households in Guangxi increased from 455 Yuan in 1980 to 26416 yuan in 2015, which increased by 58.06 times and the average annual growth rate was $12.30 \%$. The per capita net income of Guangxi farmers reached 9467 yuan in 2015, 54.41 times the 174 yuan in 1980, and the annual average growth rate was $12.09 \%$.

\subsection{Comparative Analysis of Urban and Rural Residents' Income Growth and Economic Growth in Guangxi}

Since the reform and opening up, the economy of Guangxi has developed rapidly. The per capita GDP has increased from 278 yuan in 1980 to 35190 yuan in 2015 , which has increased by 126.58 times, and the average annual growth rate is $14.83 \%$. However, the growth rate of urban residents' income in Guangxi is less than the speed of economic growth, which shows that the income of urban residents is not ideal at the same time [3]. From 1980 to 2015, the average annual growth rate of per capita GDP in Guangxi was $14.83 \%$, while the average annual growth rate of per capita disposable income of urban households in Guangxi was $12.30 \%$. The growth of rural residents' income is also slower than that of economic growth. By 2015, the per capita net income of farmers in Guangxi has increased by $12.09 \%$ annually, which is also slower than the average annual growth rate of $14.83 \%$ (see Figure 1). 


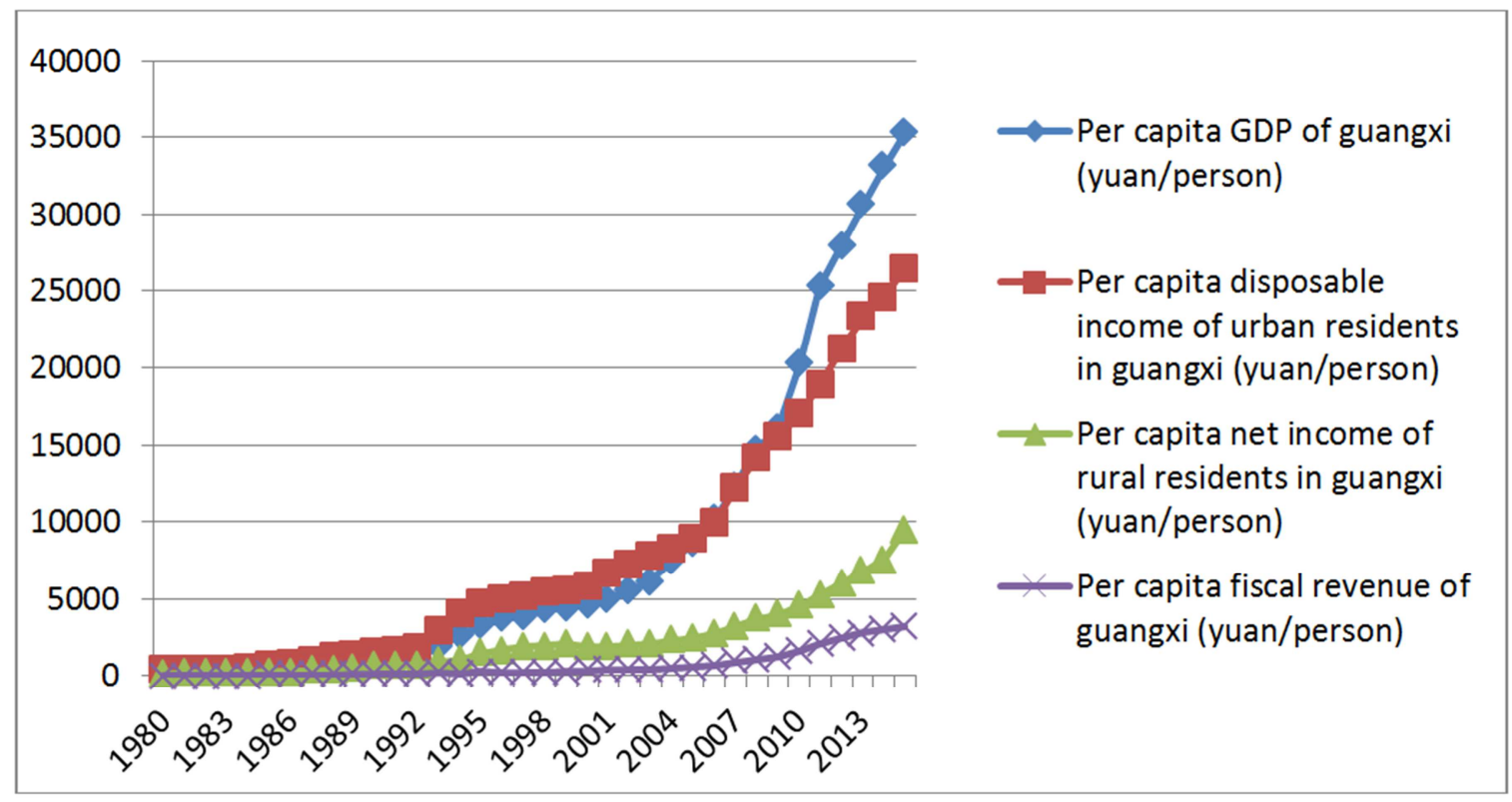

Figure 1. Guangxi's per capita GDP, household income and fiscal revenue in 1980 2015.

\subsection{An Analysis of the Growth and Change of Per Capita Fiscal Revenue}

The per capita financial income of Guangxi, from 35.55 yuan in 1980 to 3173 yuan in 2015, has increased by 89.25 times with an average annual increase of $14 \%$. It is faster than the per capita disposable income of urban residents, faster than the per capita net income of rural residents. The growth rate of each year is shown in Figure 2. As you can see from the picture, the growth rate of Guangxi's per capita fiscal revenue has a huge shock from 1993 to 1996 , from $-35.92 \%$ to $+114.66 \%$, with the magnitude of $150.58 \%$ because of the impact of tax distribution system reform in 1994. And the per capita fiscal revenue in Guangxi has not changed much in the rank of the country, which is basically in about 20th. It shows that the change of per capita fiscal revenue in Guangxi has a certain representative significance in the country.

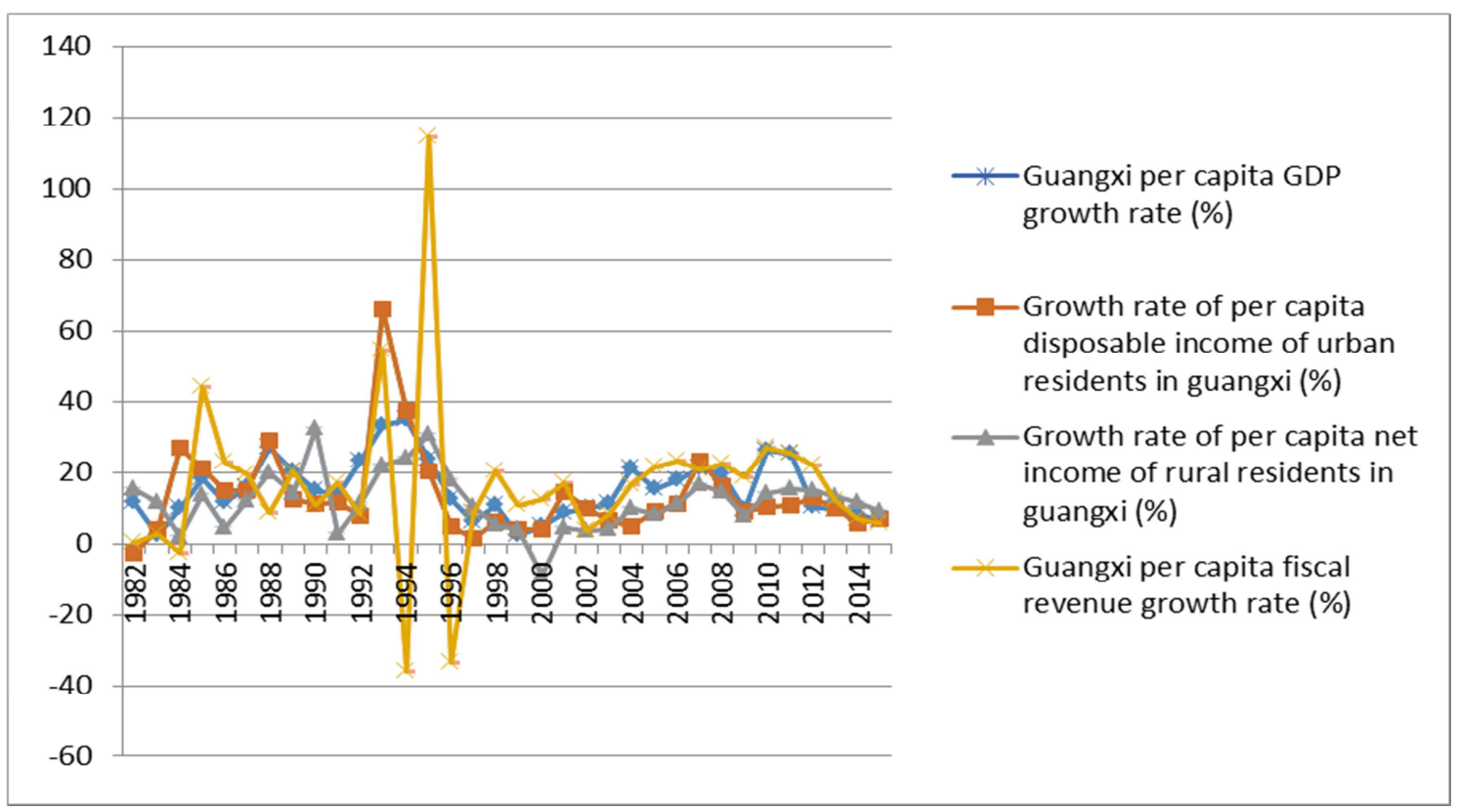

Figure 2. Annual growth rate of per capita GDP, household income and fiscal revenue in Guangxi from 1980 to 2015.

\subsection{The Analysis of the Changes in the Economic Structure of Guangxi}

The proportion of the second industry in Guangxi increased from $31.6 \%$ in 1980 to $45.9 \%$ in 2015 . The proportion of the third industry increased from $23.1 \%$ in 1980 to $38.8 \%$ in 2015 , while the first industry fell from $45.3 \%$ in 1980 to $15.3 \%$ in 2015. It can be seen that the economic structure of Guangxi has changed greatly, from agriculture to the second and third industries. 


\section{Model Construction and Empirical Analysis}

The objective of the model to be achieved: First, the quantitative characteristics of economic growth and economic structure, residents' income growth and fiscal income level. Secondly, does economic growth match the statistical data of economic structure, residents' income growth and fiscal income level. Third, whether the current economic structure, the growth of household income and the level of fiscal revenue have contributed to economic growth.

Because of the more obvious changes in the fiscal revenue before and after the 1994 tax distribution system reform, the selected data interval is 1994 2014 years (Table 2), so that the regression analysis is more comparable and more accurate. In this paper, natural logarithms are calculated for each data [6].

Table 1. Guangxi's per capita GDP, household income, fiscal revenue and economic structure from 1994 to 2014.

\begin{tabular}{|c|c|c|c|c|c|c|}
\hline Year & $\begin{array}{l}\text { Per capita GDP } \\
\text { in Guangxi (yuan } \\
\text { / person) }\end{array}$ & $\begin{array}{l}\text { Guangxi second } \\
\text { industry } \\
\text { proportion }(\%)\end{array}$ & $\begin{array}{l}\text { The proportion } \\
\text { of Guangxi third } \\
\text { industry }(\%)\end{array}$ & $\begin{array}{l}\text { Per capita disposable } \\
\text { income of Guangxi urban } \\
\text { residents (yuan / person) }\end{array}$ & $\begin{array}{l}\text { Per capita disposable } \\
\text { income of Guangxi } \\
\text { rural residents (yuan / } \\
\text { person) }\end{array}$ & $\begin{array}{l}\text { Guangxi per } \\
\text { capita fiscal } \\
\text { income (yuan / } \\
\text { person)) } \\
\end{array}$ \\
\hline & GDP & DRCY & DSCY & CZSR & NCSR & RJCZ \\
\hline 1994 & 2675 & 39.2 & 32.9 & 3981.09 & 1107.02 & 138.5 \\
\hline 1995 & 3304 & 35.8 & 34 & 4792 & 1446.14 & 297.31 \\
\hline 1996 & 3706 & 34.6 & 33.9 & 5033.33 & 1703.13 & 197.23 \\
\hline 1997 & 3928 & 33.8 & 34.1 & 5110.29 & 1875.28 & 214.01 \\
\hline 1998 & 4346 & 34.9 & 34.4 & 5412.24 & 1971.9 & 257.13 \\
\hline 1999 & 4444 & 34.6 & 36.6 & 5619.54 & 2048.33 & 284.53 \\
\hline 2000 & 4652 & 35.2 & 38 & 5834 & 1865 & 319.61 \\
\hline 2001 & 5058 & 33.8 & 40.9 & 6666 & 1944 & 373.16 \\
\hline 2003 & 6169 & 34.9 & 41.8 & 7785 & 2095 & 419.31 \\
\hline 2004 & 7461 & 36.5 & 39.7 & 8177 & 2305 & 487.94 \\
\hline 2005 & 8590 & 37.9 & 39.2 & 8917 & 2495 & 592.82 \\
\hline 2006 & 10121 & 39.6 & 38.7 & 9899 & 2771 & 730.53 \\
\hline 2007 & 12277 & 41.6 & 37 & 12200 & 3224 & 882.95 \\
\hline 2008 & 14652 & 43.3 & 36 & 14146 & 3690 & 1081.85 \\
\hline 2009 & 16045 & 43.6 & 37.6 & 15451 & 3980 & 1284.1 \\
\hline 2010 & 20219 & 47.1 & 35.4 & 17064 & 4543 & 1632.35 \\
\hline 2011 & 25326 & 48.4 & 34.1 & 18854 & 5231 & 2048.02 \\
\hline 2012 & 27951 & 47.9 & 35.4 & 21243 & 6008 & 2500.4 \\
\hline 2013 & 30588 & 46.6 & 37.6 & 23305 & 6791 & 2803 \\
\hline
\end{tabular}

Sources: China Statistical Yearbook, China Financial Yearbook and Guangxi Statistical Yearbook.

The Cobb Douglas production function is a production function created by the American mathematician C. W. Cobb and the economist Paul H. Douglas to explore the relationship between input and output. The basic form of Cobb Douglas production function is:

$$
\mathrm{Y}=A_{t} L^{\alpha} K^{\beta} \mu
$$

Formula $\mathrm{Y}$ is the gross industrial output value, is the comprehensive technical level, $\mathrm{L}$ is the number of labor input (unit is ten thousand people), and $\mathrm{K}$ is the capital input. In this paper, we introduce the equation of Cobb Douglas production function:

$\mathrm{GDP}=\mathrm{A} * \mathrm{DRCY} * \mathrm{DSCY} * \mathrm{CZSR} * \mathrm{NCSR} * \mathrm{RJCZ}$
In order to study the influence of residents' income, fiscal income and economic structure on economic growth, this paper regards capital input $\mathrm{K}$, labor input $\mathrm{L}$ and knowledge and technology $\mathrm{A}$ as exogenous variables, thus establishing regression equation, using per capita GDP, the proportion of the second industry, the proportion of the third industry, the per capita disposable income of urban residents, the per capita disposable income of rural residents. The regression equation is as follows:

\section{$\mathrm{LNGDP}=+\mathrm{LNDRCY}+\mathrm{LNDSCY}+\mathrm{LNCZSR}+\mathrm{LNNCSR}+\mathrm{LNRJCZ}$}

Using Eviews software to do regression calculation, we get the following results: 
Table 2. Eviews regression results table.

\begin{tabular}{|c|c|c|c|c|}
\hline \multicolumn{5}{|c|}{ Dependent Variable: LNGDP } \\
\hline \multicolumn{5}{|c|}{ Method: Least Squares } \\
\hline \multicolumn{5}{|c|}{ Date:08/25/18 Time:22:25 } \\
\hline \multicolumn{5}{|l|}{ Sample:1994 2014} \\
\hline \multicolumn{5}{|c|}{ Included observations:21 } \\
\hline Variable & Coefficient & Std. Error & t-Statistic & Prob. \\
\hline $\mathrm{C}$ & -5.689629 & 2.417187 & -2.353822 & 0.0326 \\
\hline LNDRCY & 0.795273 & 0.471299 & 1.687407 & 0.1122 \\
\hline LNDSCY & 0.343265 & 0.397745 & 0.863027 & 0.4017 \\
\hline LNCZSR & 0.750860 & 0.271254 & 2.768101 & 0.0144 \\
\hline LNNCSR & 0.434326 & 0.181524 & 2.392660 & 0.0303 \\
\hline LNRJCZ & 0.046487 & 0.101903 & 0.456187 & 0.6548 \\
\hline R-squared & 0.997370 & \multicolumn{2}{|c|}{ Mean dependent var } & 9.071678 \\
\hline Adjusted R-squared & 0.996493 & \multicolumn{2}{|c|}{ S.D. dependent var } & 0.806814 \\
\hline S.E. of regression & 0.047781 & \multicolumn{2}{|c|}{ Akaike info criterion } & -3.009424 \\
\hline Sum squared resid & 0.034245 & \multicolumn{2}{|c|}{ Schwarz criterion } & -2.710989 \\
\hline Log likelihood & 37.59895 & \multicolumn{2}{|c|}{ Hannan-Quinn criter. } & -2.944656 \\
\hline F-statistic & 1137.507 & \multirow{2}{*}{\multicolumn{2}{|c|}{ Durbin-Watson stat }} & 0.986924 \\
\hline Prob.(F-statistic) & 0.000000 & & & \\
\hline
\end{tabular}

Using Stata software to do regression calculation, we get the following results:

Table 3. Stata regression results table.

\begin{tabular}{ll}
\hline & $(\mathbf{1})$ \\
\hline VARIABLES & LNGDP \\
LNDRCY & 0.795 \\
& $(0.471)$ \\
LNDSCY & 0.343 \\
& $(0.398)$ \\
LNCZSR & $0.751^{* *}$ \\
LNNCSR & $(0.271)$ \\
& $0.434^{* *}$ \\
LNRJCZ & $(0.182)$ \\
& 0.0465 \\
Constant & $(0.102)$ \\
& $-5.690^{* *}$ \\
Observations & $(2.417)$ \\
R-squared & 21 \\
\hline
\end{tabular}

Standard errors in parentheses

*** $\mathrm{p}<0.01,{ }^{* *} \mathrm{p}<0.05,{ }^{*} \mathrm{p}<0.1$

The following regression models are established as follows:

$$
\begin{gathered}
\text { LNGDP }=\begin{array}{c}
-5.690 \\
(-2.35)
\end{array}+\begin{array}{c}
0.795 \mathrm{LNDRCY} \\
(1.69)
\end{array}+\begin{array}{c}
0.343 \mathrm{LNDSCY} \\
(0.86)
\end{array}+\begin{array}{c}
0.751 \mathrm{LNCZSR} \\
(2.77)
\end{array}+\begin{array}{c}
0.434 \mathrm{LNNCSR} \\
(2.39)
\end{array}+\begin{array}{c}
0.046 \mathrm{LNRJCZ} \\
(0.46)
\end{array} \\
R^{2}=0.997, \mathrm{D} . \mathrm{W}=0.987, \mathrm{~S} . \mathrm{E}=0.048, \mathrm{~F}=1137.507
\end{gathered}
$$

(Figures in brackets refer to $\mathrm{T}$ statistics corresponding to parameter estimates)

The adjoint probability of $\mathrm{F}$ statistics is less than 0.05 , which shows that the equation is significant, indicating that all the parameters to be estimated are not all zero. The value of the $\mathrm{R}$ square is 0.997 , which shows that the regression effect of the equation is good. Among them, the per capita disposable income of urban residents LNCZSR and the per capita net income of rural residents LNNCSR have significant impact on GDP (its adjoint probability of $t$ statistic is less than 0.05 ), indicating that they are closely related to economic growth.
The corresponding adjoint probability after the term "Obs * $\mathrm{R}$-squared" is greater than 0.05 , indicating that there is no (first or second order) autocorrelation.

The heteroscedasticity test can be used in the table. The corresponding adjointprobability of "Obs*R-squared" is greater than 0.05 , which shows that there is no heteroscedasticity.

The JB adjoint probability is 0.40 , which is greater than 0.05 . This shows that the random disturbance term is normal distribution.

The ADF unit root method is used to test the stability of the variables. The variables are nonstationary data and after the 
second order difference, they are stationary data. It shows that there may be cointegration relations between each data. In this paper, Johansen cointegration test is used to test the cointegration relationship between these variables, and the results reflect the cointegration relationship between LNGDP, LNDRCY, LNDSCY, LNCZSR, LNNCSR, LNRJCZ, which shows that the original regression is not a spurious regression. It also shows that although the series of variables are non-stationary, there is a long-term stable equilibrium relationship between GDP and variables.

Judging whether there is a cointegration relationship, it is to see whether the first number 293.1102 and 134.4853 of the third columns in Table 4 can be more than 5\% significant levels of critical values 83.93712 and 36.63019 . If the number is larger than the number, there is at least one cointegration relationship, and on the contrary, there is no cointegration relationship. Or see if the probability of the first line is less than 0.05 , and if it is less than 0.05 , it indicates a cointegration relationship, and vice versa (see Table 4). The cointegration test above shows that there are cointegration relations between five variables: LNGDP, LNDRCY, LNDSCY, LNCZSR, LNNCSR and LNRJCZ.

Table 4. Cointegration test results.

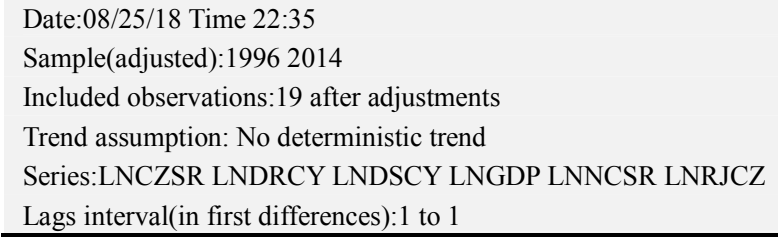

Unrestricted Cointegration Rank Test (Trace)

\begin{tabular}{lllll}
\hline Hypothesized & & Trace & $\mathbf{0 . 0 5}$ & \\
\hline No. of CE(s) & Eigenvalue & Statistic & Critical Value & Prob.** \\
\hline None* & 0.999157 & 293.1102 & 83.93712 & 0.0000 \\
At most $1^{*}$ & 0.994145 & 158.6249 & 60.06141 & 0.0000 \\
At most 2* & 0.777597 & 60.95548 & 40.17493 & 0.0001 \\
At most 3* & 0.673744 & 32.39349 & 24.27596 & 0.0038 \\
At most 4 & 0.434535 & 11.11208 & 12.32090 & 0.0790 \\
At most 5 & 0.014632 & 0.280054 & 4.129906 & 0.6574 \\
\hline
\end{tabular}

Trace test indicates 4 cointegratingeqn(s) at the 0.05 level

*denotes rejection of the hypothsis at the 0.05 level

**MacKinnon-Haug-Michelis(1999) p-values

Unrestricted Cointegration Rank Test (Maximum Eigenvalue)

\begin{tabular}{lllll}
\hline Hypothesized & \multicolumn{3}{l}{ Max-Eigen } & $\mathbf{0 . 0 5}$ \\
\hline No. of CE(s) & Eigenvalue & Statistic & $\begin{array}{l}\text { Critical } \\
\text { Value }\end{array}$ & $\begin{array}{l}\text { Prob.* } \\
*\end{array}$ \\
\hline None* & 0.999157 & 134.4853 & 36.63019 & 0.0000 \\
At most $1 *$ & 0.994145 & 97.66943 & 30.43961 & 0.0000 \\
At most 2* & 0.777597 & 28.56198 & 24.15921 & 0.0119 \\
At most 3* & 0.673744 & 21.28141 & 17.79730 & 0.0144 \\
At most 4 & 0.434535 & 10.83203 & 11.22480 & 0.0586 \\
At most 5 & 0.014632 & 0.280054 & 4.129906 & 0.6574 \\
\hline
\end{tabular}

Max-eigenvalue test indicates 4 cointegrating eqn(s) at the 0.05 level

*denotes rejection of the hypothesis at the 0.05 level

**MacKinnon-Haug-Michelis(1999) p-values

\section{Conclusion and Suggestion}

\subsection{The Income Distribution Should Be Appropriately Inclined to the Residents}

As we all know, the factors that affect economic growth are complex. Economic structure, fiscal revenue and income distribution can all have an impact on economic growth. Empirical analysis and cointegration analysis can also prove that in the long run, the above factors have an impact on economic growth, but from the short-term correlation analysis, the resident income distribution has a more significant impact on economic growth. This shows that the income distribution should be inclined to the residents properly, and in the short term it is more conducive to the economic growth. Since the reform and opening up in China, the initial distribution and redistribution of national income still slant to the government and the enterprise. The annual average growth rate of government income and enterprise income is higher than the growth of GDP. The annual average growth rate of resident income is lower than that of GDP [7].

\subsection{Make Full Use of the Means of Fiscal Adjustment of Income Distribution}

The main means and ways of adjusting the income distribution of the members of the society are taxes [8] (mainly a number of taxes that belong to the "direct tax"), such as the improvement of the existing tax collection and management system, the gradual establishment of income tax system which take the individual income tax as the main body, the property tax and social security tax as the guarantee, and other tax as a supplement. Also, it is need to consummate the consumption tax system, speed up the reform of rural tax and fee, cancel unreasonable charge, lighten the burden of farmers, improve the income of farmers, reduce the tax burden of the low income class. Other ways are the subsidy and transfer payment[9], mainly include government relief, poverty alleviation, subsidy, social security, compulsory education and so on, for example, increasing the slant strength of the central finance to the underdeveloped areas, narrowing the income gap between the regions, improving the social security system, expanding the coverage of the social security system, improving the educational situation of the low-income groups, increasing the fiscal investment to encourage full employment, and breaking the industry monopoly through fiscal policy, reducing the "access threshold", increasing the strength of poverty alleviation [10]. Transfer payment should limit the use. Special payment is used preferentially in the development of education, social security system, infrastructure construction and regional industrial economy. The last way is public expenditure. If social welfare is distributed to the public through the provision of public goods, the results of income distribution can also be adjusted. Through direct government investment or subsidies, funding public infrastructure and services, it can be beneficial for low-income families in general and thereby improve the social welfare of low-income people. 


\subsection{Increase the Incomes of Urban and Rural Residents}

Improve the employment rate of urban and rural residents, increase the wage income, property income, and business income of urban and rural residents, and improve the income of urban and rural residents through multi channels. With the development of the economy and the perfection of the income distribution system, China will realize "both the country and the people are rich" and promote the transformation of "rich country" to the "rich people", and the two are not mutually exclusive [11]. First, improve the wage income of urban and rural residents. Improve the normal wage growth mechanism increasing with the growth of the national economy, especially not to make wage growth lag behind the rate of inflation. Secondly, effectively increase the property income of urban and rural residents. Property income generally refers to income generated by capital, technology, and management, including interest, rent, dividends, property value-added income, patent income, etc.[12]Finally, improve their operating income. Improve the entrepreneurial ability of urban and rural residents. For self-employed entrepreneurs, we can consider giving certain preferential tax policies in the early stage of entrepreneurship, in order to alleviate the difficulties of entrepreneurs in the initial stage [13].

\subsection{Speedup the Optimization and Adjustment of Economic Structure}

Adjusting and optimizing the economic structure is the fundamental requirement for sustained and stable economic growth. Reasonable structure of various economic resources in various sectors and departments will help to achieve higher allocation efficiency, avoid overproduction or shortage, and make all sectors and departments get coordinated, sustained, stable and efficient development. On the other hand, if the economic structure is unbalanced, shortage or excess of some industries or departments will affect the stability, sustainability and efficiency of economic growth, and ultimately affect the entire national income. Therefore, accelerating the optimization and adjustment of economic structure is the premise of sustained and stable economic growth and the fundamental requirement of increasing the income of urban and rural residents [14]. Adjustment and optimization of economic structure include Implementing the strategy of "one belt and one road" [15], deepening the implementation of open innovation driven strategy [16], accelerating the integration and development of industrialization and urbanization, improving the development level of modern service industry.

\section{References}

[1] Zhang Chewei, Zhao WenNew. Changes in China's Income Distribution Pattern and Countermeasures [J]. Journal of Beijing University of Technology (Social Sciences Edition), 2018, 8:61-71.

[2] Shi shujie. Positive interaction between maintaining stable economic growth and optimizing income distribution structure [J]. Research and exploration, 2018, 7:126-131.

[3] Liu Jin, Shi Wenwei, Deng Xiaolian, etc. The implementation path of income doubling plan for urban and rural residents in Guangxi [J]. A reference to economic research, 2014, 37: 17-38.

[4] Li Shi. China's income distribution system reform forty years [J]. China Economist, 2018, 7:2-33.

[5] Teng Hong, Zhang long, Jiang Zhiqiang. Empirical research on China's economic growth and economic structure, fiscal revenue, household income [J]. World Survey, 2011, 2: 16-21.

[6] Zhen Kang Hua. Metrology Finance Research (Second Edition)[M]. Beijing: Economic science Press, 2014.

[7] Ouyang Huang. Coordinated growth of residents' income and national economy: Theory and demonstration [M]. Beijing: Economic science press, 2012.

[8] Yang Hong. Tax system for adjusting residents' income distribution [M]. Beijing: China tax press, 2010.

[9] Dai Yi. To promote fair income distribution, we must strengthen the function of fiscal distribution [J]. Exploration of economic issues, 2011, 4: 186-190.

[10] Zhang Huiling. Analysis of the Role of Transferred Expenditure in Adjusting Income Distribution in China [J]. Statistics and Decision Making, 2007, 6: 88-90.

[11] Liu Yue. Evolution Trend and Enlightenment of Resident Income Distribution in China since Reform and Opening-up [J]. Journal of Tianjin Commercial University, 2016, 7: 38-55.

[12] Li Shi, Zhao Renwei. Re-study on the Income Distribution of Chinese Residents [J]. Economic Research, 1999, 4: 3-17.

[13] YueXiming. How to Solve the Current Income Distribution Problem in China [J]. Financial Think Tank, 2016, 1: 129-134.

[14] GaoPeiyong, Yang Zhigang, Xia Jiechang. Frontier of China's Fiscal and Economic Theory(5) [M]. Beijing: Social Sciences Literature Press, 2008.

[15] Zhao Mingliang. Does International Investment Risk Factors have Impact on the OFDI of China to "Silk Belt and Road Initiative" Countries?: An Empirical Analysis Based on the Theory of Investment Gravity Model [J]. International economic and trade explorations. 2017, 2: 148-158.

[16] Zhao Mingliang, Zang Xu Heng. New Driving Force Shaping of International Trade and Reconstruction of Global Value Chain [J]. Reform. 2018, 7: 29-43. 